\title{
A factor analytic study of the psychological implications of the computer for the individual and society
}

\author{
MORTON WAGMAN \\ University of Illinois, Urbana-Champaign, Champaign, Illinois
}

\begin{abstract}
The coming of the computer age has provided widespread discussion of the effects on the individual and society of this most recent and powerful intellectual and technological revolution. Discussions of the psychological implications of the computer have produced a literature that is primarily polemic and, in any case, not measurement oriented with respect to identifying basic issues and central attitudes. In this article, measurement procedures including the development and testing of the Cybernetics Attitude Scale (the computer's psychological effect in each of 10 sectors of society) and a factor analytic study of the collected data are presented. The article concludes with a discussion of the research implications of the factor analytic findings and the ways in which these findings illumine the problem of the meaning of the computer for the individual and society.
\end{abstract}

The consequences of the expansion of computer presence had led Simon (1977) to refer to the changes in society due to the introduction of computers as "the information revolution" (p. 1,186). Others (Abelson \& Hammond, 1977; Davis, 1977) refer to the "information revolution" as comparable to the earlier Industrial Revolution. The impact of computers upon society has been extensive. The increasing presence of the computer and of electronics has also led to debates and disputes, sometimes extremely vociferous.

The impact of the computer upon man and upon various sectors of society has caused some to rejoice (see Sagan, 1977) and some to advise caution (see Weizenbaum, 1976). In general, there is agreement that the introduction of electronics and computers into society has had and will have many consequences. Simon (1977) sees four major areas in which the consequences will be felt: "First, there are the economic consequences that follow an innovation that increases human productivity.... Second, there are consequences for the nature of work and leisure-for the quality of life. Third, the computer may have special consequences for privacy and individual liberty. Fourth, there are consequences for man's view of himself, for his picture of the universe and of his place and goals in it" (Simon, 1977 , p. 1,189).

The research was supported by a grant from the University of Illinois Graduate College Research Board. The author wishes to acknowledge the assistance of Patricia Cavanee and William Ross in collecting and analyzing the experimental data. The author's mailing address is: University of Illinois at UrbanaChampaign, Department of Psychology, 603 East Daniel, Champaign, Illinois 61820 .
Reactions to computers have spawned a vast literature that argues both for and against their presence and usage. The general points made in each specific context are often repeated in numerous other contexts. In each context, the debate is between those in favor of computers and those against their introduction into that specific sector. In any sector, there is the question of the nature of the computer, and the consequences of its presence.

In general terms, those who are against the introduction of the computer decry its dehumanizing effects. Often they point to the limits and boundaries of its applicability. Weizenbaum (1976) points to the necessity of recognizing its limitations.

In an earlier study (Wagman, Note 1), the general literature concerned with the impact of the computer on man and society was analyzed concisely in each of 10 sectors of society. In each sector, the contrasting viewpoints of behavioral and social scientists advocating or criticizing the use of computers in that sector were analyzed with respect to their major differences. Analyses of these major issues were presented for the following sectors: computers and (1) society, (2) values, (3) cognition, (4) education, (5) medicine, (6) counseling, (7) mathematics, (8) banking, (9) politics, and (10) the criminal justice system. Thus, in the earlier study (Wagman, Note 1), an attempt was made to clarify and reduce the general literature by a summary analysis of contending viewpoints within specific sectors.

In the present article, a further clarification and reduction is achieved by representing, insofar as feasible, the specific contending viewpoints as sets of attitude scale items, each set representing advocacy or criticism of the use of computers in a specific sector of society. 


\section{METHOD}

\section{Subjects}

Sixty-three male and 58 female undergraduate students at the University of Illinois served as subjects in connection with course requirements.

\section{Materials}

The Cybernetics Attitude Scale (Wagman, Note 2) comprises 100 items, 10 items on each of 10 subscales. Each subscale is designed to measure attitudes toward computers in a specific sector of society. A subscale is composed of five statements representing positive attitudes toward computers. For each of these five statements, there is a converse statement that expresses a negative attitude toward computers. The complete Cybernetics Attitude Scale is arranged to depict groupings of items under each of the subscales (see Appendix). (As administered to subjects, items are not grouped with respect to subscales.)

Responses are scored on a 7-point Likert scale ( 1 = strongly agree with the favorable items; 1 = strongly disagree with the converse items). A high score represents negative attitudes toward computers; a low score represents positive attitudes.

\section{Procedure}

The Cybernetics Attitude Scale was administered to subjects in groups of 20 or 30 . The subjects were allowed up to $1 \mathrm{~h}$ to complete the scale. Responses were coded and anonymous. Following completion of the study, the subjects were fully debriefed.

\section{RESULTS}

\section{Descriptive Statistics}

Means and standard deviations were computed for the total scale score and for each of the 10 subscale total scores. These statistics were computed for the total sample and for men and women separately. Analyses were performed on the CYBER 170 at the University of Illinois at Urbana-Champaign. The FREQUENCIES program of the Statistical Package for the Social Sciences (Nie, Hull, Jenkins, Steinbrenner, \& Bert, 1975) was employed.

The mean (M) and the standard deviation (SD) for all subjects $(\mathrm{N}=121)$ on the total Cybernetics Attitude Scale (100 items) were 404.36 and 56.80 , respectively. The mean and standard deviation for each subscale (10 items) of the Cybernetics Attitude Scale, ranked in order from most favorable attitudes toward computer applications for that sector of society to least favorable attitudes, were: criminal justice system $(M=32.66$, SD $=7.32)$, mathematics and statistics $(M=34.31$, $\mathrm{SD}=7.83)$, politics $(\mathrm{M}=34.36, \mathrm{SD}=7.35)$, society $(M=35.60, S D=9.18)$, finance and banking $(M=$ 35.86, $S D=7.56)$, cognition $(M=42.72, S D=8.78)$, values $(M=44.05, S D=6.80)$, medicine $(M=45.73$, $\mathrm{SD}=7.20)$, education $(M=47.05, \mathrm{SD}=9.23)$, counseling $(\mathrm{M}=51.84, \mathrm{SD}=8.74)$.

Five subscales-society, values, cognition, education, and criminal justice-yielded significant differences between men and women. For each of these subscales, men had more favorable attitudes toward computer applications in that sector of society. Specific attitude scale scores were: (1) for the society subscale, men $(M=33.11, S D=8.61)$, women $(M=38.31, S D=9.04)$ ( $\mathrm{p}<.01)$; (2) for the values subscale, men $(M=42.40$, $\mathrm{SD}=6.50)$, women $(\mathrm{M}=45.85, \mathrm{SD}=6.71)(\mathrm{p}<.01)$; (3) for the cognition subscale, men $(M=40.98, S D=$ 8.34), women $(M=44.60, S D=8.93)(p<.05)$; (4) for the education subscale, men $(M=45.03, S D=9.38)$, women $(M=49.24, S D=8.61)(p<.05)$; and (5) for the criminal justice system subscale, men $(M=31.25$, $\mathrm{SD}=7.02)$, women $(\mathrm{M}=34.19, \mathrm{SD}=7.40)(\mathrm{p}<.05)$. The total scale scores were also different across sex: The mean equaled $392.52(\mathrm{SD}=53.62)$ for men versus $417.22(\mathrm{SD}=57.79)$ for women $(\mathrm{p}<.05)$.

Before one concludes that each of the subscales is truly different across sex, one must consider the correlations between the subscales. If the subscales are highly related, then the $t$ tests might be measuring the same variance several times.

The correlations between subscales ranged between .23 for criminal justice and counseling to .67 for society and values. The average correlation was .45 . Most correlations were above .40 .

\section{Principal-Components Analysis}

To further test for the independence of the subscales, two principal-components analyses were conducted on the subscale total scores. SPSS was again used. The first analysis revealed three factors.

Factor 1 had high loadings on two subscales: values (loading $=.79$ ) and cognition (loading $=.82$ ). Society and education also had highest loadings on Factor 1 compared with loadings on other factors. Society had a loading of .76 on Factor 1 and a loading of .35 on Factor 2. Education loaded .70 on Factor 1 and .44 on Factor 3.

Factor 2 included the politics subscale (with a loading of .76). Criminal justice and finance also had their highest loadings on Factor 2. Criminal justice loaded .34 on Factor 1 and .74 on Factor 2; finance loaded .79 on Factor 2 and .35 on Factor 3.

Medicine loaded .81 on Factor 3 . The counseling and mathematics subscales had split loadings: Counseling loaded .84 on Factor 3 and .32 on Factor 1. Mathematics loaded .57 on Factor 1, .37 on Factor 2, and .33 on Factor 3 . The criterion used for identifying a subscale with a particular factor was a loading above .4 on that factor and loadings below .3 on all other factors. The subscales that showed sex differences also tended to have high loadings on Factor 1. The only exception was criminal justice.

The second principal-components analysis included sex as a variable. Sex had a loading of .85 on Factor 3. So the third factor in this analysis was virtually identical to the sex variable. This analysis had the effect of separating the variance shared by the society, values, cognition, and education subscales into two parts: (1) variance shared by those variables, and also shared with the sex variable; and (2) variance shared by those 
variables due to reasons other than the sex variable (such as content similarity). All of the subscales of interest (except for criminal justice) still had moderate factor loadings on Factor 1. But they also showed high loadings on the sex factor (Factor 3). These results suggest that some of the sex differences found by the $t$ tests were reflecting common variance.

\section{Differences Between Subscales}

Dependent $t$ tests were computed (using SPSS) within the three samples. Each of these revealed that most of the subscale means were significantly different from one another. These subscales did not appear to group together on the basis of the principal-component analysis.

For the total sample, the $t$ values ranged in absolute magnitude from .33 for society versus finance (not statistically significant) to 20.05 for counseling versus mathematics $(\mathrm{p}<.001)$. For men, the absolute values range from .18 for the $t$ test comparing subscales medicine and education (not significant) to $\mathbf{1 7 . 2 5}$ for counseling versus criminal justice $(p<.001)$. For women, the lowest $t$ value in absolute magnitude occurred between the pair finance and mathematics $(t=.08$, n.s.). The largest absolute $t$ value was 13.42 , between education and criminal justice $(\mathrm{p}<.001)$.

\section{Factor Analysis}

A factor analysis was conducted on the 100 items constituting the Cybernetics Attitude Scale. Oblique rotation using DAPPFER (hydroplane fitting-Tucker, Note 2). Parallel analysis (Humphreys \& Montinelli, $1975)$ suggested the presence of five major factors. The same criterion for identifying an item with a factor was used with this analysis that had been used with the principal-components analysis. Recall that this criterion was a factor loading above .4 on one factor and loadings below .3 on all other factors. The factor analysis revealed 32 items with loadings on only one factor. These items, their factor loadings, and the subscales for which they were written are presented below.

Factor 1. The first factor was a general dimension. Computers were seen as servants of man. Four of the five items are from the values and society subscales. The fifth item (with the lowest loading) was a general mathematics item.

For Factor 1, items, subscales, and factor loadings were: "The more we use computers the more we will devalue people's worth" (values, .70); "Computers increase human freedom and allow us to become more human" (society, .64); "Compared with the industrial revolution, the computer revolution is less threatening to society" (society, .56); "Computers can never change the value of being human" (values, .49); "I would feel more comfortable doing math or statistics by computer than by hand" (mathematics and statistics, .45).

Factor 2. The second factor had three items. This factor contains items from values and counseling sub- scales. It appears to emphasize the difference between computers and humans.

For Factor 2, items, subscales, and factor loadings were: "The ability to reflect upon personal experience separates man from computers" (values, .60); "Too many things could go wrong with a computer that couldn't go wrong with a counselor as I try to solve my personal problems" (counseling, .44); "I would feel more at ease solving a personal problem with a computer than with a counselor" (counseling, .43).

Factor 3. Two areas contributed items to the third factor: (1) items based on affective reactions, and (2) items dealing with health (mental and physical) and education. The affective items often use phrases such as "I would be more at ease working with a computer," and "I would like learning from a computer." Items also appear to be similar in content. This factor consisted totally of items from the counseling, education, and medicine subscales.

For Factor 3, items, subscales, and factor loadings were: "I would like learning with a computer because I can work at my own pace" (education, .62); "I would be more at ease answering health questions from a computer than from a doctor" (medicine, .60); "Compared with a counselor, a computer would be more patient and reliable in helping to solve a personal problem" (counseling, .57); "I would feel more in control discussing my problems with a counselor than with a computer" (counseling, .55); "I would like learning from a computer because I wouldn't feel embarrassed when I didn't know the answer" (education, .53); "I would feel more independent solving a personal problem on a computer than with a counselor" (counseling, .51); "As compared with a counselor, a computer could generate a greater number of solutions to my personal problems" (counseling, .48); " I think a computer could have more information to help me solve my problems than a counselor could have" (counseling, .46); "I would be more comfortable talking to a doctor than to a computer about my health problems" (medicine, .41); "I would like working with a computer because it doesn't play favorites as a teacher might" (education, .41).

Factor 4 . The accuracy of computers is reflected in the fourth factor. Although items come from subscales as diverse as finance, politics, and mathematics, all deal with the speed and accuracy computers offer.

For Factor 4, items, subscales, and factor loadings were: "Computers can never match the accuracy of trained people in keeping records of financial transactions" (finance and banking, .61); "I would have more trust in statistics processed by a computer than by hand" (mathematics and statistics, .61); "I have more confidence when votes are counted by a computer than when they are counted by an election official" (politics, .52); "Inaccuracy is often the price paid for the speed and memory of a computer" (mathematics and statistics, .52); "When computers report the outcomes of elections instantaneously, the possiblity of naming the wrong person as a winner increases" (politics, .42); "I would 
use more caution in using computer-calculated statistics than hand-calculated statistics" (mathematics and statistics, .41).

Factor 5. The fifth factor might be considered a "memory" factor. Four of the eight items pertain to the ability of a computer to store large quantities of information. However, computer memory is not all that is reflected in Factor 5. The use of computers to benefit society could also be found in almost all of the items. This is also shown in the fact that six of the items came from the criminal justice and politics subscales.

For Factor 5, items, subscales, and factor loadings were: "I feel safer knowing the police can use the computer's high speed and extensive memory to help in the apprehension of criminals" (criminal justice, .63); "The use of computers in keeping crime statistics benefits the public" (criminal justice, .56); "When a computer instantaneously reports public opinions, both citizens and government benefit" (politics, .55); "I do not think that personal credit information stored in computers will interfere with my rights to privacy" (banking and finance, .51); "I think it is valuable to have computers forecast the outcomes of elections" (politics, .47); "Forecasting the outcomes of elections by computers interferes with the election process" (politics, .47); "I think it is desirable to have information about criminals stored in computers" (criminal justice, .46); "A computer simply can not increase a person's mental abilities" (cognition, .42).

\section{DISCUSSION}

The data can be used to examine the question of whether, among the 10 sectors of society, there exist generally differentiable rankings of advocacy or criticism of the use of computers. It appears from the data that there is advocacy for the use of computers in such sectors as the criminal justice system and mathematics and statistics, and criticism of the use of computers in such sectors as counseling and medicine. There are a number of possible explanations of these differences: There is a historical hypothesis, there is a sociological hypothesis, and, finally, there is a psychological hypothesis.

With respect to the historical hypothesis, the development of the analog computer by Vannevar Bush and the development of the modern digital computer by Norbert Weiner had as their goal the execution of complex mathematical and statistical analyses that, without the aid of computers, would be exceedingly difficult or impossible. Begun during World War II and, because of their expense, initially restricted to only a few scientific, university, and government settings, computer applications in mathematics, science, and statistics have become highly prevalent and, indeed, indispensable. Thus, in the mathematics and statistics sector of society, computers have the longest history and represent a functional use that is equivalent to their definition, that is, a computing function. This computing function was early extended beyond scientific systems to social and government systems such as the criminal justice system and to business organizations such as financial and banking systems, in each of which there is a continuity of the historical use for statistical and data-processing purposes. On the other hand, as discussed in the introduction to this article, the uses of computers in psychiatry and psychology and, especially, in the areas of counseling and medical diagnosis departs from the historic purpose of computers (numerical analysis) and represents much more recent applications and, by comparison, are probably still pioneering efforts.

A sociological hypothesis for the slow acceptance of or, indeed, resistance to the use of computers in medicalhistory taking and diagnosis, psychiatry, and counseling might include the concept of cultural lag (Ogburn, 1922), which states that the symbolic acceptance of technological innovation requires a time delay for the overcoming of the strain induced in customary behavior patterns in a particular cultural enterprise. Related sociological hypotheses are those of vested interest and social evolution (Parsons \& Smelser, 1956). As pointed out by Parsons and Smelser (1956, pp. 246-249), a vested interest within a social system may require the rejection of innovative threats to its customary behavior patterns by institutionalized rationalizations (Parsons, 1951, pp. 505-520).

A psychological hypothesis is the threat computers offer in the fields of medical diagnosis (Bleich, 1973; Card, Nicholson, \& Crean, 1974; Grossman, Barnett, McGuire, \& Swedlow, 1971), psychiatry (Erdman, Greist, Klein, Jefferson, \& Getto, 1981; Lucas, Mullins, Luna, \& McInroy, 1977), psychotherapy (Colby, 1980; Greist, 1980; Slack \& Slack, 1977), and counseling (Harris, 1978; Wagman, 1980; Wagman, 1982; Wagman \& Kerber, 1980; Wagman \& Kerber, in press). The threat is to professionals' pride in possessing unique intellectual and judgmental abilities (Blois, 1980; McDonald, 1976). This psychological hypothesis of injury to professional pride has been offered as a more general explanation of the initial resistance to the Copernican heliocentric theory, the Darwinian evolutionary theory of the descent of man, and the Freudian psychodynamic theory of unconscious determination of behavior, which initially were considered to be insults to mankind's unique dignity and significance.

The results of the factor analysis indicate clusters of attitudes that cut across several subscales or sectors of society. One such cluster is Factor 3, which represents similarity of attitudes toward computers in the medicine, education, and counseling sectors. This cluster appears to represent affective reactions toward the use of the computer in traditional professional roles, such as those of physician, teacher, psychologist, and psychiatrist. This clustering of items represents highly personal and ego-involved reactions.

Whereas Factor 3 cut across the education, medicine, and counseling sectors, Factor 5 represents a cluster of attitudes that cut across the criminal justice system and 
the politics sectors. It would appear that attitudes toward the use of computers in these sectors of society reflect storage and retrieval functions in which the computer's memory is used for the benefit of society. However, as may be seen from the converse items of the Cybernetics Attitude Scale (Appendix) for these sectors, these positive uses may imply possible deleterious uses that result in intrusion into privacy and threats to personal freedom in these sectors of society.

In Factor 4 , there is a cluster of attitudes that cut across the mathematics and statistics and the finance and banking sectors. Common to this attitude cluster is the recognition of the fundamental hallmarks of the computer, namely, its speed and accuracy in data processing. This efficiency cluster represents the power of the computer's contributions to mathematical, scientific, and engineering applications.

In contrast to Factors 4 and 5 , which seem to refer to the specific technical uses of the computer, such as its speed, accuracy, and memory, Factors 1 and 2 search out the meanings of these technical functions of the computer with respect to values and society in general. These factors seem to reflect the concern that, somehow, the intelligent functions of the computer threaten an eventual possible control, in an undesirable direction, of the human social system, or, at least, a diminution in the uniqueness of those higher cognitive processes by which the humanistic and scientific disciplines have been advanced. It is of interest that scholars in the humanities are beginning to relate themselves to the computer in such a way that its mere technical functions become an adjunct to the scholar's inquiry and judgment. Contemporary examples might include proving the authorship of poems, plays, or religious tracts by identifying common elementary features present in a set of written productions and by tracing etymological changes in classical languages over several centuries (Dilligan, 1982) and computer-aided investigations by art historians and conservators into the restoration of paintings by old masters (Cherlin, 1982).

\section{REFERENCE NOTES}

1. Wagman, M. Conceptual analysis of the psychological meaning of the computer in ten sectors of society. Unpublished manuscript, Department of Psychology, University of Illinois at Urbana-Champaign, 1981.

2. Wagman, M. The cybernetics attitude scale. Unpublished manuscript, Department of Psychology, University of Illinois at Urbana-Champaign, 1978.

3. Tucker, L. R. DAPPFER: Direct artificial personal probability factor rotations. Unpublished manuscript and computer program, Department of Psychology, University of Illinois at Urbana-Champaign, 1980.

\section{REFERENCES}

Abelson, P., \& Hammond, A. The electronics revolution. Science, 1977, 195, 1087-1092.
Bleich, H. L. The computer as a consultant. New England Journal of Medicine, 1971, 284, 141-147.

Buors, M. S. Clinical judgment and computers. New England Journal of Medicine, 1980, 303, 192-197.

Card, W. I., Nicholson, M., \& Crean, G. P. A comparison of doctor and computer interrogation of patients. International Journal of Biomedicine and Computers, 1974, 5, 175-187.

Cherlin, M. Computer-aided investigations into old master paintings. Datamation, June 1982, pp. 92-94.

Colby, K. M. Computer psychotherapists. In J. B. Sidowski, J. H. Johnson, \& T. A. Williams (Eds.), Technology in mental health care delivery systems. Norwood, N.J: Ablex, 1980.

DAvis, R. M. Evolution of computers and computing. Science, 1977, 195, 1096-1101.

Dilligan, R. Literary studies enter the computer age. Personal Computing, August 1982, pp.60-61.

Erdman, H. P., Greist, J. H., Kiein, M. G., Jefferson, J. W., \& GETTO, C. The computer psychiatrist: How far have we come? Where are we heading? How far dare we go? Behavior Research Methods \& Instrumentation, 1981, 13, 393-398.

Greist, J. H. Computer therapy. In R. Herink (Ed.), The psychotherapy handbook, New York: New American Library, 1980.

Grossman, J. G., Barnett, G. O., McGuire, M. T., \& Swedlow, D. B. Evaluation of computer-acquired patient histories. Journal of American Medical Association, 1971, 215, 1286-1291.

Harris, J. The computer: Guidance tool for the future. In J. C. Hansen (Ed.), Counseling process and procedures, New York: Macmillan, 1978.

Humphreys, L. G., \& Montinell, R. G. An investigation of parallel analysis criterion for determining the number of common factors. Multivariate Behavioral Research, 1975, 10, 193-205.

Lucas, R. W., Mullins, P. J., Luna, C. B. X., \& McInroy, D. C. Psychiatrists and a computer as interrogators of patients with alcohol-related ilnesses: A comparison. British Journal of $P_{s y-}$ chiatry, 1977, 131, 160-167.

McDonald, C. L. J. Protocol-based computer reminders, the quality of care and the non-perfectability of man. New England Journal of Medicine, 1976, 295, 1351-1355.

Nie, N. H., Hull, G. H., Jenkins, J. G., Ste inbrenner, K., \& BENT, D. H. SPSS: Statistical package for the social sciences (2nd ed.). New York: McGraw-Hill, 1975.

Oaburn, W. F. Social change, Gloucester, Mass: Smith, 1922.

Parsons, T. The social system. New York: Free Press of Glencoe, 1951.

Parsons, T., \& Smeloer, N. J. Economy and society. New York: Free Press of Glencoe, 1956.

SAGAN, C. The dragons of Eden: Speculations on the evolution of human intelligence. New York: Ballantine Books, 1977.

Simon, H. A. What computers mean for man and society, Science, 1977, 195, 1186-1190.

Stack, W. V., \& Slack, C. L. W. Talking to a computer about emotional problems: A comparative study. Psychotherapy: Theory, Research, Practice, 1977, 14, 156-164.

Wagman, M. PLATO DCS: An interactive computer system for personal counseling. Journal of Counseling Psychology, 1980, 27, 16-30.

Wagman, M. A computer method for solving dilemmas. Psychological Reports, 1982, 50, 291-298.

Whoman, M., \& Kerber, K. W. PLATO DCS: An interactive computer system for personal counseling: Further development and evaluation. Journal of Counseling Psychology, 1980, 27, 31-39.

Wagman, M., \& Kereen, K. W. The PLATO dilemma counseling system: Solving life-choice problems with the aid of a computer. In J. Crawford, S. Vitale, \& J. Robinson (Eds.), Clinical applications of computers in mental health and mental retardation. Cambridge, Mass: Ballinger, in press.

WEIZENBAUM, J. Computer power and human reason: From judgment to calculation. San Francisco: Freeman, 1976. 
Society

1. The complexity of the problems of modern society require 6 . computers for their solutions. (69)

2. There is really no reason to fear computers. (39)

3. Computers increase human freedom and allow us to become more human. (72)

4. Compared with the industrial revolution, the computer is less threatening to society. (47)

5. What is threatening to society is not the computer, but people's use of the computer. (77)

1. It is good that computers only do what they are programmed to do. (61)

2. It is not important that computers do not exercise discretionary judgment over the purpose that may have been intended. (78)

3. The dependability that a computer provides is more important than the human flexibility that is lost. (86)

4. It does not matter that computers cannot reflect upon the meaning of their personal experience. (53)

5. Computers can never change the value of being human. (95)

1. Computers are valuable because they save people from mental drudgery. (23)

2. Just because people use a computer for arithmetic problems does not mean people will forget how to do arithmetic problems. (65)

3. It is a good idea to use computers to teach concepts to grade school children. (1)

4. People's mental abilities are actually increased by interacting with the computer. (99)

5. No matter how much society uses computers, the mental capacity of society will remain as good as ever. (17)

1. I would feel more at ease solving a personal problem with a computer than with a counselor. (45)

2. I would feel more independent solving a personal problem on a computer than with a counselor. (55)

3. I think a computer could have more information to help me solve my problems than a counselor could have. (6)

4. Compared with a counselor, a computer would be more patient and reliable in helping to solve a personal problem. (41)

5. As compared with a counselor, a computer could generate a greater number of solutions to my personal problems. (80)

1. I would feel more at ease learning from a computer than from a teacher. (59)

2. I would feel more independent learning from a computer than learning from a teacher. (100)

3. I would like learning with a computer because I can work at my own pace. (97)

4. I would like learning from a computer because I wouldn't feel embarrassed when I didn't know the answer. (35)

5. I would like working with a computer because it doesn't play favorites as a teacher might. (8)

1. I would be more at ease answering health questions from a computer than from a doctor. (68)

2. I could be more frank and open when answering a computer's health questions than questions from a doctor. (10)

7. Computers are justifiably feared. (94)

8. Computers are beginning to make us less human. (37)

9. The widespread use of computers in society threatens civilization more than any other innovation. (81)

10. The most threatening thing about computers is their very existence. (98)

Values

6. It would be nice if computers didn't always do only what they are programmed to. (21)

7. Even computers should use discretionary judgment in solving social problems. (38)

8. A computer cannot replace man's flexibility in solving problems. (13)

9. The ability to reflect upon personal experience separates man from computers. (26)

10. The more we use computers the more we will devalue people's worth. (87)

Cognition

6. People have begun to rely too heavily upon computers. (31)

7. If a person does all of his math problems on a computer, he will forget how to do these problems by hand. (5)

8. Learning concepts on the computer sacrifices children's grasp of the meaning of these concepts. (63)

9. A computer simply cannot increase a person's mental abilities. (71)

10. If society uses computers too often and too much, the mental capacity of society will begin to decrease. (89)

Counseling

6. I would rather talk to a counselor than try to solve my personal problems with a computer. (40)

7. I would feel more in control discussing my problems with a counselor than with a computer. (18)

8. A counselor could know me better than a computer ever could. (44)

9. Too many things could go wrong with a computer that couldn't go wrong with a counselor as I try to solve my personal problems. (22)

10. A counselor could help me more than a computer could with my personal problems because a counselor would have more experience with my type of problem. (9)

Education

6. I would rather learn from a teacher than from a computer. (82)

7. A computer can never match the human contact a teacher provides. (20)

8. A computer structures the learning situation too much. (88)

9. I would not like to feel that a computer is smarter than me. (91)

10. Learning from a computer would be a cold and impersonal experience. (56)

Medicine

6. I would be more comfortable talking to a doctor than to a computer about my health problems. (3)

7. I would be more honest when answering questions about my health from a doctor than from a computer. (42) 
3. I feel that a computer health survey would be more systematic than a health survey taken by a doctor. (49)

4. I think that personal answers to a computer health survey would be kept in stricter confidence than answers to a doctor's survey. (14)

5. In medical diagnosis, I believe that computers are faster and more accurate than a doctor. (4)

1. I think it is valuable to have computers to forecast the outcomes of elections. (25)

2. When computers report the outcomes of elections, the democratic process is made more effective. (74)

3. I have more confidence when votes are counted by a computer than when they are counted by an election official. (34)

4. When a computer keeps records of contributions to potiticians, elections are made fairer. (52)

5. When a computer instantaneously reports public opinion both citizens and government benefit. (50)
8. A doctor would be less likely to miss important facts about my health than would a computer. (96)

9. I could not be sure who would see my answers to a computer health survey. (46)

10. A computer can never replace the experience and intuition of a good doctor. (62)

Politics

6. Forecasting the outcomes of elections by computers interferes with the election process. (27)

7. When computers report the outcomes of elections instantaneously, the possibility of naming the wrong person as winner increases. (2)

8. An election official would be less likely to make a inistake in counting ballots than a computer would. (11)

9. Keeping a computer accounting of political contributions does not deter illegal contributions. (75)

10. Reporting public opinion by computer may interfere with the functioning of the government. (54)
1. I think it is desirable to have information about criminals stored in computers. (12)

2. The use of computers in keeping crime statistics benefits the public. (15)

3. I feel safer knowing the police can use the computer's high speed and extensive memory to help in the apprehension of criminals. (51)

4. I do not think my freedom is reduced by the widespread use of computers in the justice system. (64)

5. There is really no way in which innocent citizens can be harmed by the wide use of computers in the justice system. (76)

\section{Criminal Justice System}

6. I don't think computers have a place in the justice system. (85)

7. The crime statistics kept on computers are too misleading to be much good. (36)

8. The use of the speed and memory of computers to help apprehend criminals does not really help to deter crime. (90)

9. The widespread use of computers in the justice system violates my rights. (70)

10. It is too easy to make a mistake and harm an innocent person when computers are used in the justice system. (67)

Finance and Banking

1. As compared with people, computers are more accurate 6. Computers can never match the accuracy of trained in keeping records of personal financial transactions. (57)

2. Credit and other financial transactions are faster when done through a computer than when done through people. (32)

3. Personal credit information can be kept just as private and confidential on computers as through any other medium. (24)

4. I do not think that personal credit information stored in computers will interfere with my rights to privacy. (83)

5. The danger of theft of personal funds is not increased by the use of computers in banking and credit operations. (92) people in keeping records of financial transactions. (66)

7. There are more important things to consider about financial transactions than the speed a computer can give. (16)

8. The use of computers to record personal credit information increases the possibility of other people getting hold of personal information about me. (29)

9. My rights are more easily violated when computers store personal credit information about me. (33)

10. Theft of personal funds has greatly increased since computers were introduced into credit and banking operations. (7)

Mathematics and Statistics

1. The computer's lightning swift calculating ability and nearly infinite memory are entirely desirable. (19)

2. It would be desirable to learn statistics from a computer because most statistics are calculated on computers. (30)

3. It is better to solve math or statistics problems by computer than by hand. (73)

4. I would have more trust in statistics processed by a computer than by hand. (93)

5. I would feel more comfortable doing math or statistics by computer than by hand. (79)

6. Inaccuracy is often the price paid for the speed and memory of a computer. (48)

7. Statistics should be learned and understood before a computer is used for their calculation. (58)

8. Solving statistics or math problems by hand is often better than using the computer to solve these problems. (84)

9. I would use more caution in using computer-calculated statistics than hand-calculated statistics. (43)

10. All in all, I would prefer to do math or statistics myself than use a computer. (28)

Note-Numbers given in parentheses after items refer to their placement as administered to subjects. 